\title{
Personality type matters: Perceptions of job demands, job resources, and their associations with work engagement and mental health
}

\author{
Raphael M. Herr ${ }^{1}$ (D) Annelies E. M. van Vianen ${ }^{2} \cdot$ Catherin Bosle $^{1} \cdot$ Joachim E. Fischer ${ }^{1}$
}

Accepted: 16 February 2021 / Published online: 14 April 2021

(C) The Author(s) 2021

\begin{abstract}
This three-wave study examined whether the pattern of associations of job demands and job resources with work engagement and mental health depends on personality types. In a representative sample of the German workforce $(N=13,665)$, the Big Five personality traits could be used to cluster participants into five personality types: ordinary, resilient, strained, overcontrolled, and undercontrolled. As predicted, job demands were associated with mental health and job resources were primarily associated with work engagement. However, these relationships differed across personality types. We conclude that research and practice could take a more personality-driven stance towards employee perceptions of job demands and job resources and their associations with work engagement and mental health.
\end{abstract}

Keywords Personality types $\cdot$ Job demands $\cdot$ Job resources $\cdot$ Work engagement $\cdot$ Mental health

\section{Introduction}

Healthy and motivated employees are essential for the productivity and success of a company and for reducing financial burden on the health care system and society. Consequently, research and practice aim to define and create healthy and motivating work environments in which employees get what they need to thrive in their work. To date, researchers and practitioners have been particularly focused on defining characteristics of the work environment that are beneficial (or detrimental) to all employees. Indeed, employees are well-suited for and perform best in their work if it fulfils basic human needs, such as the need for autonomy, competence, and relatedness (Deci \& Ryan, 2000). In addition to these basic needs, employees also have unique needs related to their personality and values (Van Vianen, Hamstra, \& Koen, 2016). Person-Environment fit theory (Van Vianen, 2018) proposes that people have an innate need to fit environments that match their own characteristics. A

Raphael M. Herr

raphael.herr@medma.uni-heidelberg.de

1 Mannheim Institute of Public Health, Social and Preventive Medicine, Medical Faculty Mannheim, Heidelberg University, Mannheim, Germany

2 Department of Work and Organizational Psychology, University of Amsterdam, Amsterdam, The Netherlands specific work environment can be thriving for one employee and oppressing for another, depending on an employee's personality. More research is needed that accounts for personality differences in predicting which environments are motivating and healthy for employees. This research can extend existing theory and prior empirical findings and can inform practice of how to establish an optimal match between individual employees and work characteristics.

The job demands-resources (JD-R) model categorizes workrelated characteristics into job demands and resources to predict work engagement and mental health (cf. Crawford, Lepine, \& Rich, 2010; Nahrgang, Morgeson, \& Hofmann, 2011). The JD$\mathrm{R}$ model specifies that job demands relate to mental health (named the health impairment process), while job resources relate especially to work engagement (named the motivational process) (Bakker \& Demerouti, 2017). According to the JD-R model, the health impairment process follows two paths. In the first path, high job demands provoke prolonged overtaxing, resulting in exhaustion. In the second path, a lack of resources hampers attempts to meet job demands, which in the long run leads to disengagement and withdrawal (Demerouti, Bakker, Nachreiner, \& Schaufeli, 2001).

Personality traits are proposed to impact the associations between the independent (job demands and resources) and dependent variables (mental health and work engagement) of the JD-R model. Bakker, Demerouti, and Sanz-Vergel (2014, p. 394), for example, noted that "(p)ersonality may play an important role in work engagement (...), because individuals with a 
specific personality profile may be better able to mobilize their job resources than individuals with a different profile are. For example, extraverts show positive emotions, a high frequency and intensity of personal interactions, and a high need for stimulation". Thus, some personality traits might exacerbate the association of job demands and resources with job outcomes, respectively, while others might alleviate it.

Personality theory distinguishes five basic personality traits, neuroticism, extraversion, openness, agreeableness, and conscientiousness, which are called the Big Five or the Five-Factor Model (FFM) of personality (John, Naumann, \& Soto, 2008). Traditionally, these personality types have been considered in isolation, but recently personality researchers have combined the Big Five personality traits into personality (proto)types or profiles (Asendorpf, Borkenau, Ostendorf, \& Van Aken, 2001; Gerlach, Farb, Revelle, \& Amaral, 2018; Herzberg \& Roth, 2006), each consisting of a specific combination of Big Five traits. The reduction of a large number of combinations of single personality traits into a few personality types provides advantages for research and practice. This person-centered approach examines individuals as a whole, which makes it possible to understand how individuals rather than their individual traits interact with the environment (Fisher \& Robie, 2019). Mounting empirical evidence has confirmed the existence of personality types (Gerlach et al., 2018; Isler, Fletcher, Liu, \& Sibley, 2017; Roth \& von Collani, 2007). Moreover, personality types were found to relate differently to health outcomes (Kinnunen et al., 2012).

In this study, we integrate recent developments in personality research - the existence of personality types - into the well-established JD-R model. As knowledge about the role of personality in the JD-R model is still lacking, we explore (1) differences in job demands, job resources, work engagement, and mental health across personality types and (2) the associations of job demands and resources with work engagement and mental health across personality types.

This study contributes to the literature on personality types and the JD-R model in three ways. First, this study provides a differentiated, broadened, and deepened understanding of personality differences in employee perceptions of the work environment. Second, this study examines whether job demands and job resources relate differently to work engagement and mental health, depending on an employee's personality type. Third, the findings of this study may challenge the current "one size fits all approach" in research and practice and can inform practice on tailored work engagement and health promoting interventions.

\section{The Job Demands-Resources Model}

The job demands-resources (JD-R) model (Demerouti et al., 2001) is one of the best-established frameworks describing the association between work characteristics and mental health and work engagement. The heart of this model is the idea that factors contributing to stress, mental health, and work engagement can be classified into two categories: job demands and job resources (Bakker \& Demerouti, 2017; Demerouti et al., 2001). Job demands are physical, social, or organizational job aspects that are mentally or physically demanding and are therefore accompanied by physiological and psychological expenditures (Bakker, Demerouti, \& Euwema, 2005). In contrast, job resources are physical, social, or organizational job aspects that are beneficial in buffering the link between job demands and the related physiological and psychological expenditures. In addition, job resources facilitate achievement of work aims, motivate personal development and growth, and promote work engagement (Bakker et al., 2005). Two processes translate work characteristics into negative work outcomes such as mental exhaustion and disengagement, respectively. The health impairment process refers to high demands, which deplete mental and physical resources leading to exhaustion and ill-health. The motivational impairment process is characterized by low resources, which impairs work engagement (Bakker \& Demerouti, 2008; Bakker, Demerouti, \& Schaufeli, 2003). The JD-R model proposes that demands are especially related to mental health, while resources are especially related to work engagement. An additional proposition of the model is that job resources reduce the negative association between job demands and mental health (Bakker et al., 2005). This model has received extensive empirical support and has been generalized to different work populations (for an overview see Bakker \& Demerouti, 2017).

\section{Personality Traits and Types, and Occupational Health}

Individual personality traits can determine how individuals perceive and interpret their (work) environment, handle stress, and subsequently how mentally healthy they are (c.f., Ozer \& Benet-Martinez, 2006). Moreover, individual personality traits affect how individuals experience their work characteristics: whether they are experienced as demands or as resources (Mäkikangas, Feldt, Kinnunen, \& Mauno, 2013).

The best-established model to describe personality is the Big Five model, also called the Five-Factor Model (FFM) (Goldberg, 1990; Matthews, Deary, \& Whiteman, 2003; McCrae \& Costa Jr, 2008). This model distinguishes five personality traits: neuroticism, extraversion, openness to experience, agreeableness, and conscientiousness. Neuroticism is characterized by trait adjectives such as: tense, anxious, nervous, moody, and worrying. Extraversion encompasses trait adjectives such as talkative, assertive, active, energetic, and outgoing. Openness to experience includes trait adjectives such as wide interests, imaginative, intelligent, and original. 
Agreeableness refers to trait adjectives such as sympathetic, kind, appreciative, affectionate, and soft-hearted. Conscientiousness concerns trait adjectives such as organized, thorough, planful, and efficient (John et al., 2008).

These traits are linked to job performance, well-being, and health (e.g., Albrecht \& Marty, 2020; Bakker, Van Der Zee, Lewig, \& Dollard, 2006; Barrick \& Mount, 1991; Goodwin \& Friedman, 2006; Timothy A Judge, Higgins, Thoresen, \& Barrick, 1999; Taris \& Schaufeli, 2016). Especially the trait neuroticism has been identified to have negative effects on health and engagement (Inceoglu \& Warr, 2011; H. J. Kim, Shin, \& Swanger, 2009). People high on this trait are characterized by a relatively stable tendency to react to frustration, threat, or loss with negative emotions (Lahey, 2009). Hence, neuroticism is expected to relate to the affective and motivational components of engagement (Inceoglu \& Warr, 2011). Additionally, Bakker et al. (2006) found that neuroticism was related to burnout. Also, conscientiousness and extraversion have been linked to work engagement (Inceoglu \& Warr, 2011; H. J. Kim et al., 2009). However, based on the Conservation of Resources theory (Hobfoll, 1989) that asserts reciprocal associations between resources and outcomes, and a review of longitudinal studies, Mäkikangas et al. (2013) conclude that personality and work engagement are reciprocally related and are likely to accumulate.

The Big Five model characterizes individuals according to five isolated traits, reflecting a variable-centered approach to personality. However, other personality researchers characterize individuals according to typical combinations of these traits, which reflect a typology or person-centered approach to personality. They use cluster analytic methods to determine valid personality types. The so-called ARC model - named after authors of the studies underlying this model Asendorpf et al. (2001), Robins, John, Caspi, Moffitt, and StouthamerLoeber (1996); Caspi and Silva (1995) (c.f., Gerlach et al., 2018) - differentiates three personality types: resilient, overcontrolled, and undercontrolled. Resilient individuals are typically low on neuroticism and high on extraversion, agreeableness, and conscientiousness, and have medium or slightly increased values in openness to experience. Overcontrolled individuals are characterized by low extraversion and high neuroticism. Undercontrolled individuals have low values particularly on agreeableness and consciousness.

Based on a literature review and empirical investigation, Herzberg and Roth (2006) extended the ARC model with the personality types confident and reserved. Confident individuals have medium values on neuroticism, agreeableness and consciousness and moderately high values on extraversion and openness. This personality type resembles the personality type identified by other authors, who labelled it as assertive or resilient undercontrolled (Gramzow et al., 2004; Schnabel, Asendorpf, \& Ostendorf, 2002). Reserved individuals are characterised by low neuroticism, extraversion and openness and moderately high values on agreeableness and conscientiousness. The resilient type is similar to the resilient overcontrolled or the well adjusted type in other examinations (Gramzow et al., 2004; Schnabel et al., 2002). Recently, Gerlach et al. (2018) found evidence for four distinct personality types by applying an alternate computational clustering approach to data from more than 1.5 million people. They redefine the ARC-types into role model, self-centred, and reserved, and extend this typology by the average personality type, characterised by average values on all traits. Taken together, although there is no final consensus about the number and description of the personality types, the different models do share some basic characteristics of personality types. Additional research with different samples can further confirm or uncover the existence of specific personality types.

Kinnunen et al. (2012) who were among the first to investigate the relation between personality types and health concluded that the personality type approach revealed more nuanced associations with health than the variable-centered approach. Their study among Finnish adults identified five personality types: resilient (neuroticism low, other traits high), overcontrolled (neuroticism high, other traits low), reserved (conscientiousness high, low on other traits), undercontrolled (openness and extraversion high, conscientiousness low), and ordinary (average on all traits) (Kinnunen et al., 2012). These personality types were stable over time (measured at age 33, 42 and 50) and they were differently related to subjective health (psychological distress, self-rated health, and symptoms reporting). Resilient individuals reported the best and overcontrolled stated the worst health over eight years.

The present study examines the combination of personality traits into personality types. Furthermore it extends prior research (Kinnunen et al., 2012) by relating personality types to both work engagement and mental health and by taking personality type into account when analyzing the association between employees' experienced work environment and their work engagement and mental health.

\section{The Present Study}

The present study aims to identify personality types based on the Big Five traits in a representative sample of employees in German companies with more than 50 employees (Bellmann et al., 2015; Kampkötter, Mohrenweiser, Sliwka, Steffes, \& Wolter, 2016). The perception of the work characteristics and work engagement, as well as mental health across the personality types are examined. In addition, the relation of job demands and job resources with work engagement and mental health are examined separately for each personality type in three consecutive waves. Based on the literature discussed above, the development of confirmatory hypotheses does not appear advisable and we therefore formulated explorative 
research questions. If the previous findings on personality types are generally valid, it should also be possible to replicate the types in this (occupational) sample. Our research question is:

Research question 1: Can the Big Five personality traits be clustered into specific personality types?

Previous research has shown that personality traits are related to perceptions of job demands and resources, well-being and work engagement (Bakker et al., 2010; Janssens, De Zutter, Geens, Vogt, \& Braeckman, 2019; Weiss, Bates, \& Luciano, 2008; Wilmot, Wanberg, Kammeyer-Mueller, \& Ones, 2019). Based on these findings, we assume a relationship between personality types and these work-related perceptions. Our second research question is:

Research question 2. Do perceptions of job demands and resources, and work engagement and mental health differ for specific personality types?

Personality types were found to be differently related to subjective health (Kinnunen et al., 2012). This might be due to differences in perceptions of work characteristics (job demands and resources), as we suggest above. For example, a specific personality type may experience more job demands and fewer resources than other personality types in similar work conditions, leading to lower subjective health. However, it is also possible that personality types differ in the extent to which perceptions of work characteristics are related to mental health and work engagement. For example, employees may experience a similar high amount of work pressure but this may impact the health outcomes of a specific personality type more than those of other personality types. Our third research question is:

Research question 3. Do the associations of job demands and job resources with work engagement and mental health differ for specific personality types?

\section{Methods}

\section{Participants and Procedure}

In this study, three waves from the Linked Personnel Panel (LPP) were used. The LPP is a longitudinal survey, which is representative for companies from the private sector in Germany that have more than 50 employees (Kampkötter et al., 2016). The sample was drawn from the Institute for Employment Research Establishment Panel, an annual representative survey of around 16,000 German companies representing all industries and sizes nationwide (Bellmann et al., 2015; Fischer, Janik, Müller, \& Schmucker, 2009). Companies with less than 50 employees and from the business sectors of agriculture, forestry and fishery, as well as civil service and charity organisations were excluded. The sample was stratified according to sector, size and region (Bellmann et al., 2015; Kampkötter et al., 2016).

The first wave was conducted in 2012/2013 among 7508 employees. The second wave was in 2014/2015 among 7282 employees and the last wave was in 2016/2017, collecting data of 6779 employees. In total, 13,999 employees (71.2\% men, with an average age of $45.53(\mathrm{SD}=10.78)$, ranging from 18 to 74 years; $61.8 \%$ white-collar; $87.2 \%$ work full time) participated in one or more waves and 13,665 employees were available for identifying personality types by means of cluster analysis. Of these, 4207 employees $(73.1 \%$ men, with an average age of $46.19(\mathrm{SD}=9.55)$, ranging from 20 to 63 years; $64.2 \%$ white-collar; $88.2 \%$ full time) were eligible for longitudinal analyses across three waves. All participants gave informed consent, and the Ethics Commission of the Medical Faculty Mannheim of the University of Heidelberg (2018514N-MA) approved the secondary data analysis.

\section{Measurements}

The measurements concerned work characteristics, personality traits, work engagement and mental health. Personality traits were assessed at baseline whereas the other variables were measured at each wave. All scales, except mental health, were measured on a five-point Likert scale of which most ranged from "does not apply at all" (1) to "applies completely" (5).

Work Characteristics The Job Demands-Resources Model specifies work characteristics in terms of job demands and job resources (e.g., Demerouti et al., 2001). The items for measuring job demands and job resources were chosen based on theoretical reasoning and statistical exploration (i.e., exploratory factor analysis using a maximum likelihood estimation with varimax rotation, see the Appendix Table 5). Job demands concerned physical demands and work-home interference. Physical demands comprised two items (job requires physical effort, and to be exposed to unpleasant conditions, Cronbach's alpha $=.69$ ) (Morgeson \& Humphrey, 2006). Work-home interference was assessed with five items (e.g., having time pressure, or work demands interfere with home and family life, Cronbach's alpha $=.76$ ) (Morgeson \& Humphrey, 2006; Netemeyer, Boles, \& McMurrian, 1996). Job resources were operationalized as work autonomy and variety, fairness at work, leadership and company culture, development opportunities, and peer support. Work autonomy and variety are two core job characteristics of Hackman and Oldham's Job Characteristics Model 
(Hackman \& Oldham, 1976). We combined the two items reflecting these job characteristics ("job allows to make own decisions" and "job involves a great deal of task variety"; Morgeson \& Humphrey, 2006) into a composite scale, work autonomy and variety. The Cronbach's alpha of this scale was .47. Fairness at work included three items (e.g., being rewarded fairly at work, or rules and procedures to make decisions are fair, Cronbach's alpha $=.65$ ) (Kim \& Leung, 2007). Leadership and company culture were assessed with seven items (e.g., "supervisors have confidence in those they manage" and "all are aware of the long-term plans and direction of the company", Cronbach's alpha = .84). Development opportunities were assessed with three items (e.g., "the company is interested in development of professional knowledge and competences", Cronbach's alpha = .74). Finally, peer support was measured by two items ("receiving help and support from colleagues if required" and "offering help to colleagues", Cronbach's alpha $=.68$ ). For all scales, mean scores were calculated and higher values indicate higher perceptions on the respective dimensions.

Personality Traits Big Five personality traits (neuroticism, extraversion, openness to experience, agreeableness, and conscientiousness) were measured at the first wave with 16 items from the Big Five Inventory short scale (BFI-S) (Gerlitz \& Schupp, 2005). Neuroticism (Cronbach's alpha $=.56$ ), extraversion (Cronbach's alpha $=.60$ ), agreeableness (Cronbach's alpha $=.42$ ), and conscientiousness (Cronbach's alpha $=.54$ ) were measured with three items, openness to experience (Cronbach's alpha $=.54$ ) with four items. The low internal consistencies are comparable to those of the initial study in which the scales were developed (neuroticism $=.61$, extraversion $=.69$, agreeableness $=.53$, conscientiousness $=.59$, openness to experience $=.65$ (Richter, Metzing, Weinhardt, $\&$ Schupp, 2013)). Note that short personality scales generally have low alpha values (Kampkötter et al., 2016; Lang, John, Lüdtke, Schupp, \& Wagner, 2011). The first reason is that the Cronbach's alpha value is dependent of the number of items with shorter scales having lower values. The second reason is that Cronbach's alpha values decreases with the heterogeneity of the items. Broad personality dimensions are composite measures including various items representing the construct. Despite the lower alpha values of short personality scales, these scales have shown the expected relationships with pertinent measurements (Gosling, Rentfrow, \& Swann, 2003; Kampkötter et al., 2016). Mean values were calculated with higher values indicating a higher personality trait characteristic.

Work Engagement Work engagement was measured by nine items taken from the Utrecht Work Engagement Short Scale (UWES-9) (Schaufeli \& Bakker, 2004a, 2004b). The dimensions vigour (e.g., "At my work, I feel bursting with energy"), dedication (e.g., "I am enthusiastic about my job"), and absorption (e.g., "I get carried away when I'm working") were measured with three items each. All items were rated on a five-point Likert scale, asking how often employees feel or experience the respective statement: (1) every day, (2) several times a week, (3) several times a month, (4) a few times a year, (5) never. Ratings were reversed and a mean score was calculated with higher scores representing more work engagement. Cronbach's alpha for the scale was .91.

Mental Health Mental health was assessed by the 1998 version of WHO-5-Well-Being Questionnaire (Topp, Østergaard, Søndergaard, \& Bech, 2015). Participants rated five items how they felt the last two weeks on a six-point scale (from 0 "at no time" to 5 "all of the time"): cheerful and in good spirits; calm and relaxed; active and vigorous; woke up feeling fresh and rested; daily life has been filled with things that interest me. Cronbach's alpha for the scale was .84. In line with Topp et al. (2015), the items were summed and multiplied by four to obtain values in the range from 0 to 100 , where higher values are indicative for better mental health.

\section{Statistical Analyses}

The personality types were identified by an established clustering procedure (Asendorpf et al., 2001; Barbaranelli, 2002; Rammstedt, Riemann, Angleitner, \& Borkenau, 2004; Sârbescu \& Boncu, 2018). Personality scales were transformed by z- standardization and Ward's hierarchical clustering was combined with non-hierarchical K-means clustering to avoid potential suboptimal solutions of hierarchical models (Asendorpf et al., 2001). The results from the Ward's hierarchical clustering were used as the cluster centers for nonhierarchical k-means clustering (Asendorpf et al., 2001; Barbaranelli, 2002; Rammstedt et al., 2004; Sârbescu \& Boncu, 2018).

The number of clusters was determined by the two-step approach as recommended by Herzberg and Roth (2006). In the first step, the cluster solutions at least moderately replicable were selected (Cohn's $\mathrm{K} \geq 0.6$ (Asendorpf et al., 2001)). In the second step, internal fit measures were applied (Duda and Hart's stopping rule) (Duda, Hart, \& Stork, 2001).

For each identified personality type, separate fixed-effect regression analyses were conducted, estimating the association of work characteristics (job demands and job resources) with work engagement and mental health across the three waves. These panel data regressions allow estimating the covariation of the independent (work characteristics) and dependent (work engagement and mental health) variables (Allison, 2009; Herr, Bosch, Theorell, \& Loerbroks, 2018). Utilizing within-person variation inherently eliminates time-invariant factors from the analysis (Allison, 2009; Herr et al., 2018; Wooldridge, 2010). All time stable variables (e.g., gender, 
working branch, or genetic set up) which were not measured (i.e., omitted variables) are thus eliminated because each individual is used as its own control (Allison, 2009; Herr, Almer, et al., 2018; Herr, Bosch, et al., 2018). Regressions based on zstandardized variables were adjusted for age (in years) to take into account the career stage in which individuals were, which can influence their perception of the psychosocial work environment (e.g., Loerbroks et al., 2010). The statistical analyses were performed using the software package Stata version 14 (S.E.).

\section{Results}

Table 1 presents the descriptive statistics and bivariate correlations of studied variables in the total sample. As expected, job demands were negatively and job resources were positively associated with work engagement and mental health. Personality traits were related to job demands, job resources, and outcomes, but in varying degrees and directions.

\section{Personality Types}

A five-cluster solution nearly reached the acceptable agreement of Cohn's $\mathrm{K}=0.60$ (Cohn's $\mathrm{K}=0.583$; adjusted Rand Index $=0.358$ ) (Asendorpf et al., 2001; Herzberg \& Roth, 2006). The Duda and Hart stopping rule index (Je[2]/Je[1]) was 0.86 (pseudo $\mathrm{T}$ squared $=992.84$ ) for this solution. The second best solution had three clusters (Cohn's $\mathrm{K}=0.557$, adjusted Rand Index $=0.357$ ) with a Duda and Hart stopping rule index of 0.78 (pseudo T squared $=1093.40$ ).

The clusters of the preferable five-cluster solution appear theoretically sound and were retrieved in prior studies. The pattern of the mean z-scores of this solution is presented in Fig. 1. In the first cluster $(N=3658 ; 27 \%)$, participants had low neuroticism and average values on the other personality traits. This type is similar to the ordinary personality type of Kinnunen et al. (2012). The second cluster $(N=2823 ; 21 \%)$ has low neuroticism values and values above-average on the other traits. This type represents the resilient ARC personality type. The third cluster $(N=2237 ; 16 \%)$ has very low agreeableness values, while all other traits are above average. This type reflects the strained personality type (Sava \& Popa, 2011). The last two clusters correspond to the ARC personality types overcontrolled $(N=2313 ; 17 \%)$ and undercontrolled $(N=$ $2634 ; 19 \%)$. The overcontrolled personality type is characterized by low values in extraversion and high values in neuroticism, and the undercontrolled personality type has relatively high values on neuroticism and low values on agreeableness and openness and very low values on conscientious and extraversion (Rammstedt et al., 2004). Taken together, these results answer the first research question that the Big Five personality traits can be clustered into specific personality types.

\section{Differences between Personality Types}

Across the personality types, slight differences in age were observed $\left(\mathrm{F}_{(4,4206)}=2.43, p=.046\right)$. Individuals in the overcontrolled personality type cluster were on average the oldest, and individuals in the strained personality type cluster the youngest (mean ages were $46.96(\mathrm{SD}=9.38)$ and 45.39 $(\mathrm{SD}=9.97)$, respectively). Also, there were gender differences in the distribution of personality types $\left(\mathrm{X}^{2}=55.60\right.$, $p<.001)$. Most males were ordinary $(31.0 \%)$, followed by undercontrolled $(21.0 \%)$, resilient $(18.9 \%)$, strained $(14.6 \%)$ and overcontrolled (14.5\%). Most women were overcontrolled $(21.7 \%)$, closely followed by ordinary $(25.4 \%)$, resilient $(19.4 \%)$, strained $(18.2 \%)$ and undercontrolled $(15.3 \%)$.

Significant differences in job demands, job resources, work engagement, and mental health were found across the personality types (Table 2), which answer our second research question. The strained personality type experienced the highest job demands, whereas the resilient personality type reported to have most job resources. The undercontrolled personality type experienced lowest job resources. Highest work engagement was reported by the resilient personality type and lowest work engagement was reported by the undercontrolled personality type. The strained personality type reported the second highest work engagement, before the ordinary and overcontrolled personality types, who had very similar ratings. Regarding mental health, the resilient personality type reported the highest values, followed by the ordinary, strained and the overcontrolled type. The undercontrolled type reported the lowest mental health.

The longitudinal associations of job demands and job resources with work engagement and mental health were generally in line with JD-R theory: resources were primarily related to work engagement (Table 3), whereas job demands were associated with mental health (Table 4). However, the strength of these associations was different across personality types, answering the third research question. Both job demands were significantly related to work engagement for the ordinary personality type; that is, an increase in physical demands and work-home interference was associated with reduced work engagement $(e y / d x=-0.073, p=.014$ and $e y / d x=-0.050$, $p=.027$, respectively). An increase in physical demands was also related to reduced work engagement for the strained and overcontrolled personality types (ey/dx $=-0.087, p=0.041$ and $e y / d x=-0.091, p=.021$, respectively), whereas an increase in work-home interference was associated with reduced work engagement for the undercontrolled personality type $(e y / d x=$ $-0.099, p=.001)$. None of the demands were associated with work engagement for the resilient personality type.

With only a few exceptions, resources were positively associated with work engagement. For the ordinary personality type, all resources were related with work engagement, with 


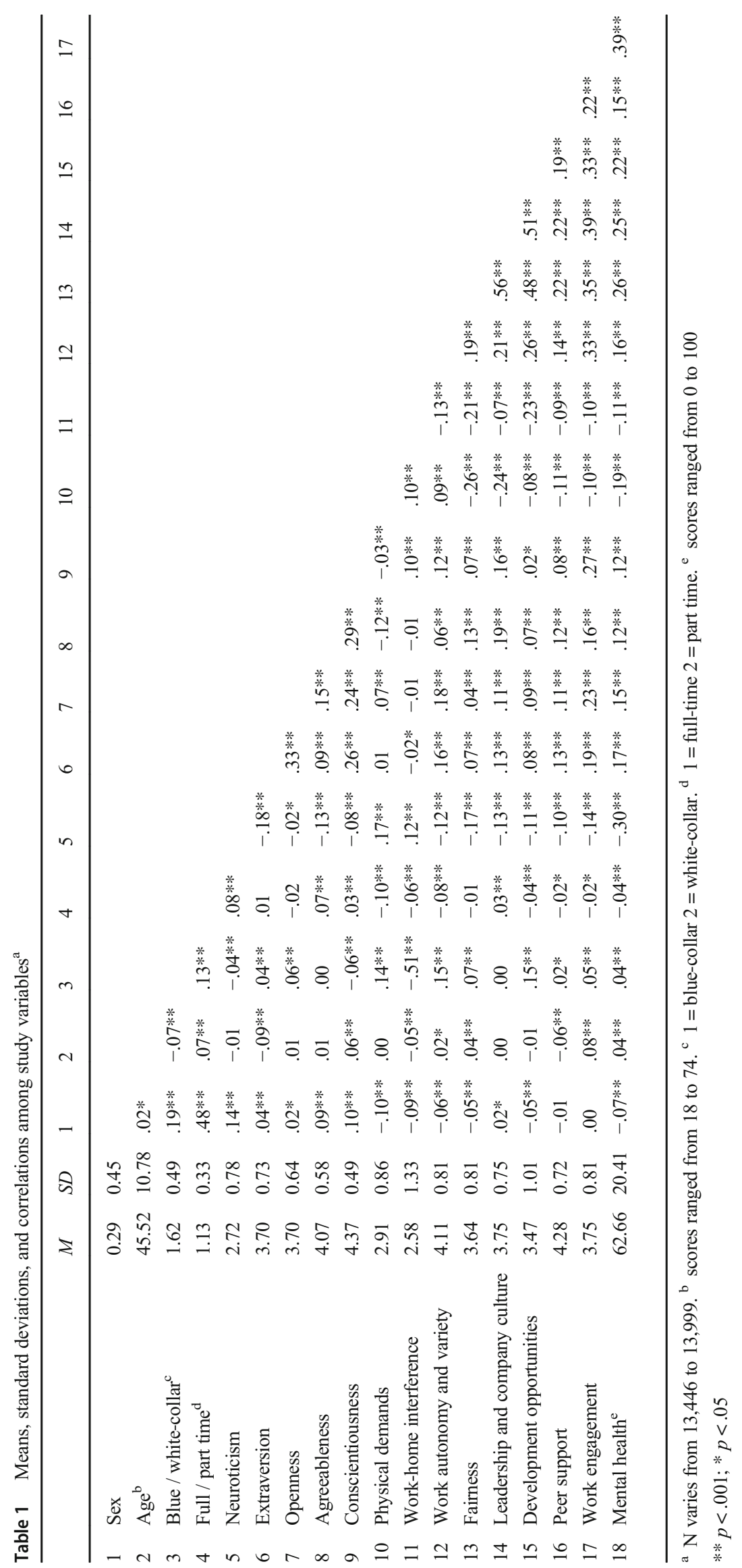




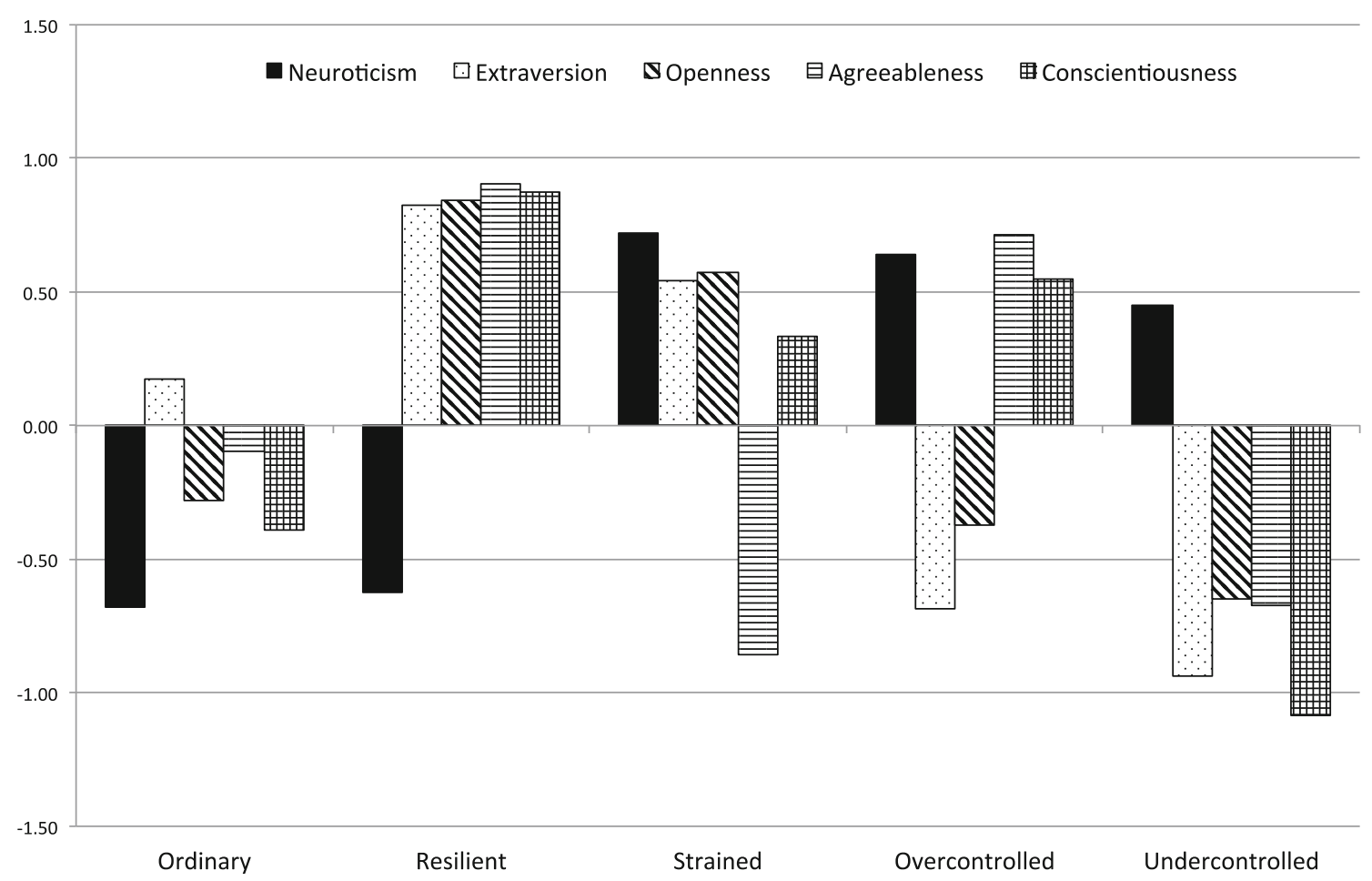

Fig. 1 Five personality types by the big-five z-scores

the strongest association for leadership and company culture $(e y / d x=0.110, p<0.001)$, and fairness $(e y / d x=0.101$, $p<.001)$. For the resilient personality type, leadership and company culture, as well as development opportunities were not associated with work engagement, whereas the other resources were, with the strongest association for fairness $(\mathrm{ey} /$ $d x=0.150, p<.001)$. For the strained and the overcontrolled personality types, all resources were associated with work engagement and for the undercontrolled personality type only peer support showed no relationship with work engagement.
Regarding mental health, an increase in physical demands was associated with reduced mental health for the ordinary personality type $(e y / d x=-0.112, p=.006)$, and the undercontrolled personality type $(e y / d x=-0.117$, $p=.041)$. Except for the resilient personality type, an increase in work-home interference was associated with reduced mental health.

As already mentioned, associations between resources and mental health were limited. However, work autonomy and variety as well as fairness were positively associated with

Table 2 Differences in job demands, job resources, work engagement, and mental health, across personality types

\begin{tabular}{|c|c|c|c|c|c|c|c|c|c|c|c|c|}
\hline & \multicolumn{2}{|c|}{$\begin{array}{l}\text { Ordinary }(n= \\
1240)\end{array}$} & \multicolumn{2}{|c|}{$\begin{array}{l}\text { Resilient ( } n= \\
800)\end{array}$} & \multicolumn{2}{|c|}{$\begin{array}{l}\text { Strained }(n= \\
656)\end{array}$} & \multicolumn{2}{|c|}{$\begin{array}{l}\text { Overcontrolled }(n= \\
693)\end{array}$} & \multicolumn{2}{|c|}{$\begin{array}{l}\text { Undercontrolled }(n= \\
818)\end{array}$} & \multicolumn{2}{|c|}{$\begin{array}{l}\text { Test for } \\
\text { differences }\end{array}$} \\
\hline & $M$ & $S D$ & $M$ & $S D$ & $M$ & $S D$ & $M$ & $S D$ & $M$ & $S D$ & F-value & $p$ \\
\hline \multicolumn{13}{|l|}{ Job Demands } \\
\hline Physical demands & 2.29 & 1.23 & 2.41 & 1.37 & 2.65 & 1.40 & 2.62 & 1.37 & 2.46 & 1.22 & 11.23 & $<.001$ \\
\hline Work-home interference & 2.47 & 0.76 & 2.43 & 0.88 & 2.73 & 0.84 & 2.55 & 0.87 & 2.60 & 0.79 & 15.73 & $<.001$ \\
\hline \multicolumn{13}{|l|}{ Job Resources } \\
\hline Work autonomy and variety & 4.17 & 0.70 & 4.42 & 0.70 & 4.27 & 0.74 & 4.04 & 0.81 & 3.94 & 0.74 & 50.18 & $<.001$ \\
\hline Fairness & 3.73 & 0.70 & 3.91 & 0.81 & 3.58 & 0.80 & 3.62 & 0.82 & 3.53 & 0.67 & 31.57 & $<.001$ \\
\hline Leadership and company culture & 3.72 & 0.64 & 4.03 & 0.73 & 3.71 & 0.77 & 3.72 & 0.77 & 3.48 & 0.64 & 62.4 & $<.001$ \\
\hline Development opportunities & 3.59 & 0.86 & 3.80 & 0.97 & 3.46 & 1.03 & 3.40 & 1.06 & 3.40 & 0.88 & 24.91 & $<.001$ \\
\hline Peer support & 4.32 & 0.64 & 4.52 & 0.62 & 4.30 & 0.69 & 4.29 & 0.72 & 4.13 & 0.67 & 34.06 & $<.001$ \\
\hline Work engagement & 3.74 & 0.72 & 4.18 & 0.69 & 3.87 & 0.71 & 3.71 & 0.82 & 3.36 & 0.76 & 128.89 & $<.001$ \\
\hline Mental health & 66.09 & 16.31 & 71.77 & 19.06 & 61.32 & 20.60 & 58.75 & 19.88 & 56.33 & 18.40 & 89.77 & $<.001$ \\
\hline
\end{tabular}

$N=4207$ 
Table 3 Associations of job demands and job resources with work engagement across personality types

\begin{tabular}{|c|c|c|c|c|c|c|c|c|c|c|c|c|c|c|c|}
\hline \multirow[t]{2}{*}{ Work engagement } & \multicolumn{3}{|c|}{$\begin{array}{l}\text { Ordinary (obs. }= \\
2896, n=1240 \text { ) }\end{array}$} & \multicolumn{3}{|c|}{$\begin{array}{l}\text { Resilient (obs. }=1824 \\
n=800)\end{array}$} & \multicolumn{3}{|c|}{$\begin{array}{l}\text { Strained (obs. }= \\
1493, n=656)\end{array}$} & \multicolumn{3}{|c|}{$\begin{array}{l}\text { Overcontrolled (obs. } \\
=1572, n=693 \text { ) }\end{array}$} & \multicolumn{3}{|c|}{$\begin{array}{l}\text { Undercontrolled } \\
\text { (obs. }=1905, n=818)\end{array}$} \\
\hline & $e y / d x$ & $S E$ & $p$ & $e y / d x$ & $S E$ & $p$ & $e y / d x$ & $S E$ & $p$ & $e y / d x$ & $S E$ & $p$ & $e y / d x$ & $S E$ & $p$ \\
\hline \multicolumn{16}{|l|}{ Job Demands } \\
\hline Physical demands & -0.073 & 0.030 & .014 & 0.019 & 0.034 & .588 & -0.087 & 0.043 & .041 & -0.091 & 0.039 & .021 & 0.011 & 0.039 & .787 \\
\hline Work-home interference & -0.050 & 0.023 & .027 & -0.039 & 0.026 & .142 & -0.013 & 0.031 & .682 & -0.022 & 0.029 & .455 & -0.099 & 0.029 & .001 \\
\hline \multicolumn{16}{|l|}{ Job Resources } \\
\hline Work autonomy and variety & 0.072 & 0.019 & $<.001$ & 0.093 & 0.023 & $<.001$ & 0.058 & 0.027 & .033 & 0.072 & 0.024 & .002 & 0.050 & 0.024 & .037 \\
\hline Fairness & 0.101 & 0.023 & $<.001$ & 0.150 & 0.026 & $<.001$ & 0.070 & 0.030 & .018 & 0.115 & 0.029 & $<.001$ & 0.069 & 0.029 & .016 \\
\hline $\begin{array}{l}\text { Leadership and company } \\
\text { culture }\end{array}$ & 0.110 & 0.025 & $<.001$ & 0.036 & 0.029 & .212 & 0.085 & 0.032 & .008 & 0.127 & 0.031 & $<.001$ & 0.096 & 0.030 & .001 \\
\hline Development opportunities & 0.061 & 0.022 & .006 & 0.021 & 0.023 & .361 & 0.094 & 0.028 & .001 & 0.065 & 0.027 & .017 & 0.071 & 0.026 & .006 \\
\hline Peer support & 0.046 & 0.017 & .007 & 0.053 & 0.022 & .015 & 0.049 & 0.024 & .040 & 0.049 & 0.023 & .032 & 0.027 & 0.021 & .192 \\
\hline
\end{tabular}

Results from fixed effects regressions across three waves. Analyses were adjusted for age

mental health for the ordinary personality type $(e y / d x=0.073$, $p=0.005 ; e y / d x=0.072, p=.020$; respectively). Work autonomy and variety were positively related to mental health for the resilient personality type $(e y / d x=0.078, p=.041)$, and leadership and company culture were positively related to mental health for the overcontrolled and undercontrolled personality types $(e y / d x=0.104, p=0.027 ; e y / d x=0.134$, $p=.002$; respectively).

\section{Discussion}

This study revealed that the Big Five personality traits can be clustered into specific personality types. Furthermore, the results showed that different personality types perceive job demands and resources differently and, accordingly, also differ in work engagement and mental health. Moreover, the associations between job demands and resources and outcomes (work engagement and mental health) seem to depend on an employee's personality profile. In line with the JD-R model, within the different personality types job demands were primarily associated with mental health, whereas job resources were primarily associated with work engagement.

Employees belonging to the ordinary personality type (relatively low neuroticism and average on other traits) were, compared to employees belonging to the other personality types, in the middle to upper middle range regarding their assessment of job demands and resources, work engagement, and mental health. For this group, lower physical demands and work-home interferences and more job resources were positively associated with their work engagement. Also, lower job demands and more work autonomy and variety, as well as fairness were positively related to mental health.

The resilient personality type felt more engaged and reported a better mental health than the other personality types. Not surprisingly, they had relatively low assessments of job

Table 4 Associations of job demands and job resources with mental health across personality types

\begin{tabular}{|c|c|c|c|c|c|c|c|c|c|c|c|c|c|c|c|}
\hline \multirow[t]{2}{*}{ Mental health } & \multicolumn{3}{|c|}{$\begin{array}{l}\text { Ordinary (obs. }= \\
2896, n=1240)\end{array}$} & \multicolumn{3}{|c|}{$\begin{array}{l}\text { Resilient (obs. }= \\
1824, n=800)\end{array}$} & \multicolumn{3}{|c|}{$\begin{array}{l}\text { Strained (obs. }=1493, \\
n=656)\end{array}$} & \multicolumn{3}{|c|}{$\begin{array}{l}\text { Overcontrolled (obs. } \\
=1572, n=693 \text { ) }\end{array}$} & \multicolumn{3}{|c|}{$\begin{array}{l}\text { Undercontrolled } \\
(\text { obs. }=1905, n=818)\end{array}$} \\
\hline & $e y / d x$ & $S E$ & $p$ & $e y / d x$ & $S E$ & $p$ & $e y / d x$ & $S E$ & $p$ & $e y / d x$ & $S E$ & $p$ & $e y / d x$ & $S E$ & $p$ \\
\hline \multicolumn{16}{|l|}{ Job Demands } \\
\hline Physical demands & -0.112 & 0.040 & .006 & -0.032 & 0.057 & .576 & -0.064 & 0.063 & .308 & -0.016 & 0.060 & .786 & -0.117 & 0.057 & .041 \\
\hline Work-home interference & -0.071 & 0.031 & .023 & -0.084 & 0.044 & .053 & -0.164 & 0.045 & $<.001$ & -0.171 & 0.044 & $<.001$ & -0.093 & 0.043 & .030 \\
\hline \multicolumn{16}{|l|}{ Job Resources } \\
\hline Work autonomy and variety & 0.073 & 0.026 & .005 & 0.078 & 0.038 & .041 & 0.070 & 0.040 & .078 & 0.016 & 0.036 & .650 & 0.047 & 0.035 & .177 \\
\hline Fairness & 0.072 & 0.031 & .020 & 0.072 & 0.043 & .093 & 0.038 & 0.044 & .390 & -0.029 & 0.043 & .504 & 0.071 & 0.042 & .091 \\
\hline Leadership and company culture & 0.059 & 0.034 & .082 & 0.036 & 0.047 & .447 & 0.012 & 0.047 & .805 & 0.104 & 0.047 & .027 & 0.134 & 0.043 & .002 \\
\hline Development opportunities & 0.019 & 0.030 & .536 & -0.005 & 0.039 & .887 & 0.067 & 0.041 & .104 & 0.055 & 0.041 & .180 & -0.004 & 0.038 & .920 \\
\hline Peer support & 0.040 & 0.024 & .093 & 0.055 & 0.036 & .120 & 0.061 & 0.035 & .083 & 0.042 & 0.034 & .222 & 0.028 & 0.030 & .344 \\
\hline
\end{tabular}

Results from fixed effects regression across three waves. Analyses were adjusted for age 
demands (although physical demands were assessed lower by the ordinary personality type) and high assessments of job resources. For this personality type, job demands were unrelated to work engagement and mental health. As suggested by their name, this group seems indeed resilient. Employees belonging to this group occupy personality traits (low neuroticism and high agreeableness, extraversion, conscientiousness, and openness to experience) that are beneficial for well-being, functioning, and health (Oshio, Taku, Hirano, \& Saeed, 2018). Regardless of their resilient traits, the work engagement of these employees could be enhanced by more autonomy, variety, and fairness, as well as more peer support. More autonomy and variety were also associated with better mental health.

The strained personality type (relatively low agreeableness and above-average values on other traits) reported average assessments of work engagement and mental health. While these employees reported average assessments of experienced job resources, they rated their job demands higher than the other personality types. People low on agreeableness are characterized as egocentric, irritable and competitive (e.g., Bruck \& Allen, 2003) and since job demands may obstruct the pursuit of personal interests and goals (due to high openness and conscientiousness), they may experience job demands - especially work-home interference - as more taxing than their agreeable counterparts who are helpful, cooperative and good-natured. For the strained personality type, physical demands were associated with lower work engagement, and work-home interference was associated with lower mental health. Work engagement was enhanced to the extent that employees perceived more job resources, such as autonomy and variety, fairness, leadership and company culture, development opportunities and peer support.

The overcontrolled personality type (high neuroticism, low extraversion) assessed work engagement and mental health relatively low. Moreover, employees belonging to this personality type assessed job demands above average and job resources below average. These results are in line with prior research showing that both neuroticism and extraversion are related to perceptions of job demands and resources, and happiness, work engagement, and well-being (Bakker et al., 2010; Janssens et al., 2019; Weiss et al., 2008; Wilmot et al., 2019). Moreover, physical demands related negatively to work engagement, while all job resources related positively to work engagement. However, few relationships existed between job demands and resources and mental health. Only a reduction in work-home interference and improved leadership and company culture were related to better mental health.

Employees with an undercontrolled personality type (low extraversion, openness, agreeableness, conscientiousness, and high neuroticism) reported the lowest work engagement and worst mental health. Compared to the other personality types, the employees in this group judged their demands to be relatively high (but less high than strained employees) and their job resources to be lowest. Employees low on agreeableness are less communion-striving and employees low on conscientiousness are less achievement-striving. The combination of low agreeableness and conscientiousness hinders interpersonal interactions and negatively affects the functioning of work teams (Penney, David, \& Witt, 2011). In addition, the low extraversion implies that persons in this group are reserved and interact less. Also, employees who are high on neuroticism and low on extraversion are disposed to be less satisfied with their job (Timothy A. Judge, Heller, \& Mount, 2002). This may explain why undercontrolled employees report suboptimal work conditions. With the exception of peer support, all resources had a positive relation with work engagement. However, both work engagement and mental health of the undercontrolled personality type benefited most from a positive leadership and company culture. In addition, better mental health was associated with lower job demands.

While differences in the perception of work characteristics were observed across the different personality types it is unclear whether personality colors the perception of the work environment or whether employees with a specific personality select themselves into specific jobs, e.g., with little resources and high demands. However, by applying a fixed-effect approach our analyses control for time stable confounding factors in the associations of work characteristics with engagement and mental health. In consequence, these findings represent a strong indication for the independent associations of work characteristics with work engagement and mental health.

\section{Theoretical Implications}

In accordance with the scientific literature, five prototypical personality types were identified and could be described in line with previous findings (e.g., Herzberg \& Roth, 2006; Roth \& von Collani, 2007). This finding points to a universal classification of the Big Five personality characteristics into personality types, especially since our sample does not concern the general population, but a working population.

Given that personality types perceived job demands and job resources differently and that these work conditions related differently to work engagement and mental health by personality types suggest that the JD-R model should include personality type as a significant variable. Depending on the research question at hand, researchers could treat personality type as an important control variable or moderator, or they could conduct multi-group comparisons when testing the JD-R model. Furthermore, future research on the JD-R model could use primarily within-person designs to account for individual level factors. That is, personality type could be treated as a random-effect variable in multi-level analyses. 


\section{Practical Implications}

Personality characteristics are relatively stable. Both personenvironment fit theory (e.g., Van Vianen, 2018) and strengths use theory (Bakker \& van Woerkom, 2018) argue that employees fare better if their personality matches their work context. Although the resilient personality type likely easily adapts to various work contexts, the other personality types may need to match work environments that fulfil their specific needs. For example, the results of this study show that although the ordinary type perceived relatively lower job demands, these job demands were associated with both work engagement and mental health. These results indicate that the ordinary type will thrive best in jobs with relatively lower physical demands and less work-home interference. However, the results of this study also show that a positive work context in which employees experience autonomy and variety, fairness, support from their supervisor and peers, and development opportunities, fulfils the needs of all employees, irrespective of their personality. Consequently, while organizations may want to attract resilient personality types in particular, also other personality types can be attracted because these personality types can be as engaged and healthy as the resilient type when the work context fulfils their universal and idiosyncratic needs (see Van Vianen, 2018). Moreover, a positive work context such as a strong justice climate can mitigate the possible negative outcomes (e.g., emotional exhaustion) of personality heterogeneity in teams (David et al., 2019).

\section{Limitations and Future Directions}

This study is not without limitations. First, personality traits were measured with an abbreviated questionnaire, substituting measuring accuracy with questionnaire length in terms of number of items and resulting in lower internal consistencies. Cronbach's alphas ranged between .42 and .60. However, our results corroborate the five personality types that were found in prior research, which indicate that our findings are trustworthy and offer further support for the generalizability of previous findings. Yet, future studies should measure the Big Five personality traits more comprehensively and test the robustness of the personality types among different samples. Second, we found relatively few significant relationships between job demands and outcomes for the different personality types, which might be due to the low number of job demands that were involved in this study. Therefore, future research should include other job demands that are known to affect work engagement and mental health, such as workload (e.g., O'Connor, Jimmieson, \& White, 2018) and emotional demands (e.g., Schaufeli \& Bakker, 2004a, 2004b).

\section{Conclusion}

In conclusion, this study provided evidence for the existence of personality types. In addition, it showed the significance of distinguishing personality types for employees' perception of the work environment (demands and resources), work engagement and mental health, and how perceptions of the work environment relate to work engagement and mental health. The findings suggest that the JD-R model should incorporate personality type as a relevant moderator. Furthermore, the findings underline the importance of job resources for the work engagement and mental health of all employees but also show that organizations could pay more attention to the match between employee personality type and work conditions.

\section{Appendix}

Table 5 Description, factor loadings, and Cronbach's alpha for job demands and job resources

\begin{tabular}{|c|c|c|c|c|c|c|c|c|}
\hline & mean & $\mathrm{SD}$ & $\begin{array}{l}\text { Factor } \\
1\end{array}$ & $\begin{array}{l}\text { Factor } \\
2\end{array}$ & $\begin{array}{l}\text { Factor } \\
3\end{array}$ & $\begin{array}{l}\text { Factor } \\
4\end{array}$ & $\begin{array}{l}\text { Factor } \\
5\end{array}$ & alpha \\
\hline \multicolumn{9}{|l|}{ Job demands } \\
\hline Physical demands & 2.91 & 0.86 & & & & & & .693 \\
\hline Job requires physical effort & & & & .839 & & & & \\
\hline Exposed to unpleasant conditions (e.g., noise, extreme temperature, odors) & & & & .823 & & & & \\
\hline Work-home interference & 2.58 & 1.33 & & & & & & .758 \\
\hline Having time pressure / several tasks at the same time & & & .561 & & & & & \\
\hline Work demands interfere with home and family life & & & .824 & & & & & \\
\hline Time for job makes it difficult to fulfill family responsibilities & & & .831 & & & & & \\
\hline Job strain makes it difficult to fulfill family duties & & & .831 & & & & & \\
\hline Having many business obligations in leisure time & & & .488 & -.404 & & & & \\
\hline
\end{tabular}


Table 5 (continued)

$\begin{array}{lllllll}\text { mean SD } & \text { Factor } & \text { Factor } & \text { Factor } & \text { Factor } & \text { Factor } \\ & 1 & 2 & 3 & 4 & 5\end{array}$

\footnotetext{
Job resources

Work autonomy and variety

Job allows to make own decisions

Job involves a great deal of task variety

Fairness

Being rewarded fairly at work

Rules and procedures to make decisions are fair

Supervisor treats me is fair

Leadership and company culture

Supervisors have confidence in those they manage

Supervisors give good guidance

Supervisors show understanding of employees

The supervisor clearly communicate requirements and objectives

Supervisors talk to people if dissatisfied

All employees have good understanding of what the organization is trying to do

All employees are aware of the long-term plans and direction of the company

Development opportunities

The company is interested in development of professional knowledge and competences

Employees expected to fit a new position best are predominantly promoted

Employees characterized by outstanding job performance are predominantly promoted

Peer support

Receiving help and support from colleagues if required

Offering help to colleagues
}

$4.11 \quad 0.81$

470

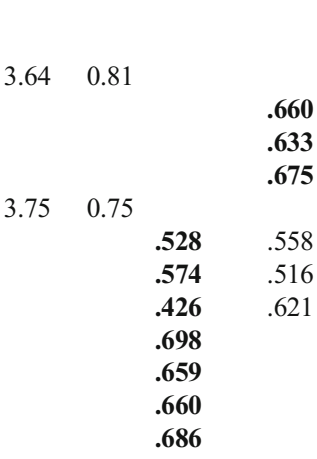

$3.47 \quad 1.01$

.361

.539

.834

.814
.744

.823

.742

$4.28 \quad 0.72$

.834

881

$N=13,922$. Rotated factors loadings $\geq .3$ are shown; bold values indicate the factor chosen for a dimension; some leadership items (supervisors have confidence in those they manage, supervisors give good guidance, supervisors show understanding of employees) load high on the fairness factor, but based on theoretical reason the fairness factor only comprised the three fairness items and the concerned leadership items were assigned to the leadership and company culture factor

Acknowledgements This study used the first three waves of the Linked Personnel Panel (LPP) (wave 1213, 1415, and 1617, DOI: https://doi.org/ 10.5164/IAB.LPP1617.de.en.v1), a longitudinal panel initiated by the German Federal Ministry of Labour and Social Affairs (BMAS) and administered at the Institute for Employment Research (IAB). This work was supported by a grant from the Federal Ministry of Labor and Social Affairs. The funders had no role in the analyses, decision to publish, or preparation of the manuscript. The authors thank Hannah Boltze for her support in preparing this manuscript.

Funding Open Access funding enabled and organized by Projekt DEAL. This work was supported by a grant from the Federal Ministry of Labour and Social Affairs. The funders had no role in analysis, decision to publish, or preparation of the manuscript.

Data Availability The data that support the findings of this study are available from the Research Data Centre (FDZ) of the German Federal Employment Agency (BA) at the Institute for Employment Research (IAB). Data used for this study can be assessed on request (http://fdz. iab.de).

\section{Declarations}

Ethics Approval This study was performed in line with the principles of the Declaration of Helsinki. Approval was granted by the Ethics Commission of the Medical Faculty Mannheim of the University of Heidelberg (2018-514 N-MA).

Consent to Participate All participants gave informed consent.
Consent for Publication Publication has been approved by all coauthors.

Conflict of Interest Joachim E. Fischer has received royalties for lectures regarding occupational health from various companies and public agents. The authors declare that they have no conflict of interest.

Open Access This article is licensed under a Creative Commons Attribution 4.0 International License, which permits use, sharing, adaptation, distribution and reproduction in any medium or format, as long as you give appropriate credit to the original author(s) and the source, provide a link to the Creative Commons licence, and indicate if changes were made. The images or other third party material in this article are included in the article's Creative Commons licence, unless indicated otherwise in a credit line to the material. If material is not included in the article's Creative Commons licence and your intended use is not permitted by statutory regulation or exceeds the permitted use, you will need to obtain permission directly from the copyright holder. To view a copy of this licence, visit http://creativecommons.org/licenses/by/4.0/.

\section{References}

Albrecht, S. L., \& Marty, A. (2020). Personality, self-efficacy and job resources and their associations with employee engagement, affective commitment and turnover intentions. The International Journal of Human Resource Management, 31(5), 657-681. https://doi.org/ 10.1080/09585192.2017.1362660. 
Allison, P. D. (2009). Fixed effects regression models: Quantitative applications in the social sciences (Vol. 160). Los Angeles: SAGE publications.

Asendorpf, J. B., Borkenau, P., Ostendorf, F., \& Van Aken, M. A. (2001). Carving personality description at its joints: Confirmation of three replicable personality prototypes for both children and adults. European Journal of Personality, 15(3), 169-198. https://doi.org/ 10.1002/per.408

Bakker, A. B., Boyd, C. M., Dollard, M., Gillespie, N., Winefield, A. H., \& Stough, C. (2010). The role of personality in the job demandsresources model: A study of Australian academic staff. Career Development International, 15(7), 622-636. https://doi.org/10. 1108/13620431011094050.

Bakker, A. B., \& Demerouti, E. (2008). Towards a model of work engagement. Career Development International, 13(3), 209-223. https://doi.org/10.1108/13620430810870476.

Bakker, A. B., \& Demerouti, E. (2017). Job demands-resources theory: Taking stock and looking forward. Journal of Occupational Health Psychology, 22(3), 273-285. https://doi.org/10.1037/ocp0000056.

Bakker, A. B., Demerouti, E., \& Euwema, M. C. (2005). Job resources buffer the impact of job demands on burnout. Journal of Occupational Health Psychology, 10(2), 170-180. https://doi.org/ 10.1037/1076-8998.10.2.170.

Bakker, A. B., Demerouti, E., \& Sanz-Vergel, A. I. (2014). Burnout and work engagement: The JD-R approach. The Annual Review of Organizational Psychology and Organizational Behavior, 1(1), 389-411. https://doi.org/10.1146/annurev-orgpsych-031413091235.

Bakker, A. B., Demerouti, E., \& Schaufeli, W. (2003). Dual processes at work in a call Centre: An application of the job demands-resources model. European Journal of Work and Organizational Psychology, 12(4), 393-417. https://doi.org/10.1080/13594320344000165.

Bakker, A. B., Van Der Zee, K. I., Lewig, K. A., \& Dollard, M. F. (2006). The relationship between the big five personality factors and burnout: A study among volunteer counselors. The Journal of Social Psychology, 146(1), 31-50. https://doi.org/10.3200/SOCP.146.1. 31-50.

Bakker, A. B., \& van Woerkom, M. (2018). Strengths use in organizations: A positive approach of occupational health. Canadian Psychology/Psychologie Canadienne, 59(1), 38-46. https://doi. org/10.1037/cap0000120.

Barbaranelli, C. (2002). Evaluating cluster analysis solutions: An application to the Italian NEO personality inventory. European Journal of Personality, 16(S1), S43-S55. https://doi.org/10.1002/per.449.

Barrick, M. R., \& Mount, M. K. (1991). The big five personality dimensions and job performance: A meta-analysis. Personnel Psychology, 44(1), 1-26. https://doi.org/10.1111/j.1744-6570.1991.tb00688.x.

Bellmann, L., Bender, S., Bossler, M., Broszeit, S., Dickmann, C., Gensicke, M., ... Laske, K. (2015). LPP-linked personnel panel. Quality of Work and Economic Success: Longitudinal Study in German Establishments (Data Collection on the First Wave). FDZ method reports, 5, 2015.

Bruck, C. S., \& Allen, T. D. (2003). The relationship between big five personality traits, negative affectivity, type a behavior, and workfamily conflict. Journal of Vocational Behavior, 63(3), 457-472. https://doi.org/10.1016/S0001-8791(02)00040-4.

Caspi, A., \& Silva, P. A. (1995). Temperamental qualities at age three predict personality traits in young adulthood: Longitudinal evidence from a birth cohort. Child Development, 66(2), 486-498. https://doi. org/10.1111/j.1467-8624.1995.tb00885.x.

Crawford, E. R., Lepine, J. A., \& Rich, B. L. (2010). Linking job demands and resources to employee engagement and burnout: A theoretical extension and meta-analytic test. Journal of Applied Psychology, 95(5), 834-848. https://doi.org/10.1037/a0019364.

David, E. M., Avery, D. R., Witt, L. A., Tonidandel, S., McKay, P. F., Brown, L., \& Crepeau, L. (2019). Helping misfits to commit: How justice climate attenuates the effects of personality dissimilarity on organizational commitment. Journal of Business and Psychology, 34(4), 503-517. https://doi.org/10.1007/s10869-018-9556-7.

Deci, E. L., \& Ryan, R. M. (2000). The "what" and "why" of goal pursuits: Human needs and the self-determination of behavior. Psychological Inquiry, 11(4), 227-268. https://doi.org/10.1207/ S15327965PLI1104 01.

Demerouti, E., Bakker, A. B., Nachreiner, F., \& Schaufeli, W. B. (2001). The job demands-resources model of burnout. Journal of Applied Psychology, 86(3), 499-512.

Duda, R. O., Hart, P. E., \& Stork, D. G. (2001). Pattern classification. New York: Wiley.

Fischer, G., Janik, F., Müller, D., \& Schmucker, A. (2009). The IAB establishment panel - things users should know. Journal of Contextual Economics, 129(1), 133.

Fisher, P. A., \& Robie, C. (2019). A latent profile analysis of the five factor model of personality: A constructive replication and extension. Personality and Individual Differences, 139, 343-348. https:// doi.org/10.1016/j.paid.2018.12.002.

Gerlach, M., Farb, B., Revelle, W., \& Amaral, L. A. N. (2018). A robust data-driven approach identifies four personality types across four large data sets. Nature Human Behaviour, 2(10), 735-742. https:// doi.org/10.1038/s41562-018-0419-Z.

Gerlitz, J.-Y., \& Schupp, J. R. (2005). Zur Erhebung der Big-Fivebasierten Persönlichkeitsmerkmale im SOEP [The measurement of the Big Five personality traits in the SOEP]. Retrieved from https:// www.diw.de/documents/publikationen/73/diw_01.c.43490.de/rn4. pdf. Accessed 3 July 2019.

Goldberg, L. R. (1990). An alternative" description of personality": The big-five factor structure. Journal of Personality and Social Psychology, 59(6), 1216-1229. https://doi.org/10.1037/0022-3514. 59.6.1216.

Goodwin, R. D., \& Friedman, H. S. (2006). Health status and the fivefactor personality traits in a nationally representative sample. Journal of Health Psychology, 11(5), 643-654. https://doi.org/10. 1177/1359105306066610.

Gosling, S. D., Rentfrow, P. J., \& Swann, W. B. (2003). A very brief measure of the big-five personality domains. Journal of Research in Personality, 37(6), 504-528. https://doi.org/10.1016/S00926566(03)00046-1.

Gramzow, R. H., Sedikides, C., Panter, A. T., Sathy, V., Harris, J., \& Insko, C. A. (2004). Patterns of self-regulation and the big five. European Journal of Personality, 18(5), 367-385. https://doi.org/ 10.1002/per.513.

Hackman, J. R., \& Oldham, G. R. (1976). Motivation through the design of work: Test of a theory. Organizational Behavior and Human Performance, 16(2), 250-279. https://doi.org/10.1016/00305073(76)90016-7.

Herr, R. M., Almer, C., Loerbroks, A., Barrech, A., Elfantel, I., Siegrist, J., Gündel, H., Angerer, P., \& Li, J. (2018). Associations of work stress with hair cortisol concentrations-initial findings from a prospective study. Psychoneuroendocrinology, 89, 134-137. https:// doi.org/10.1016/j.psyneuen.2018.01.011.

Herr, R. M., Bosch, J. A., Theorell, T., \& Loerbroks, A. (2018). Bidirectional associations between psychological distress and hearing problems: An 18-year longitudinal analysis of the British household panel survey. International Journal of Audiology, 57(11), 816824. https://doi.org/10.1080/14992027.2018.1490034.

Herzberg, P. Y., \& Roth, M. (2006). Beyond resilients, undercontrollers, and overcontrollers? An extension of personality prototype research. European Journal of Personality, 20(1), 5-28. https://doi.org/10. 1002/per.557.

Hobfoll, S. E. (1989). Conservation of resources: A new attempt at conceptualizing stress. American Psychologist, 44(3), 513-524. 
Inceoglu, I., \& Warr, P. (2011). Personality and job engagement. Journal of Personnel Psychology, 10(4), 177-181. https://doi.org/10.1027/ 1866-5888/a000045.

Isler, L., Fletcher, G. J., Liu, J. H., \& Sibley, C. G. (2017). Validation of the four-profile configuration of personality types within the fivefactor model. Personality and Individual Differences, 106, 257-262. https://doi.org/10.1016/j.paid.2016.10.058.

Janssens, H., De Zutter, P., Geens, T., Vogt, G., \& Braeckman, L. (2019). Do personality traits determine work engagement? Results from a Belgian study. Journal of Occupational and Environmental Medicine, 61(1), 29-34. https://doi.org/10.1097/jom. 0000000000001458.

John, O. P., Naumann, L. P., \& Soto, C. J. (2008). Paradigm shift to the integrative big five trait taxonomy: History, Measurment, and conceptual issues. In O. P. John, R. W. Robins, \& P. A. Lawrence (Eds.), Handbook of personality: Theory and research (Vol. 3, pp. 114-158). New York: The Guilford Press.

Judge, T. A., Heller, D., \& Mount, M. K. (2002). Five-factor model of personality and job satisfaction: A meta-analysis. Journal of Applied Psychology, 87(3), 530-541. https://doi.org/10.1037/0021-9010.87. 3.530 .

Judge, T. A., Higgins, C. A., Thoresen, C. J., \& Barrick, M. R. (1999). The big five personality traits, general mental ability, and career success across the life span. Personnel Psychology, 52(3), 621652. https://doi.org/10.1111/j.1744-6570.1999.tb00174.x.

Kampkötter, P., Mohrenweiser, J., Sliwka, D., Steffes, S., \& Wolter, S. (2016). Measuring the use of human resources practices and employee attitudes: The linked personnel panel. Evidence-based HRM: a Global Forum for Empirical Scholarship, 4(2), 94-115. https:// doi.org/10.1108/EBHRM-09-2015-0037.

Kim, H. J., Shin, K. H., \& Swanger, N. (2009). Burnout and engagement: A comparative analysis using the big five personality dimensions. International Journal of Hospitality Management, 28(1), 96-104. https://doi.org/10.1016/j.ijhm.2008.06.001.

Kim, T.-Y., \& Leung, K. (2007). Forming and reacting to overall fairness: A cross-cultural comparison. Organizational Behavior and Human Decision Processes, 104(1), 83-95. https://doi.org/10.1016/j.obhdp. 2007.01.004.

Kinnunen, M. L., Metsäpelto, R. L., Feldt, T., Kokko, K., Tolvanen, A., Kinnunen, U., ... Pulkkinen, L. (2012). Personality profiles and health: Longitudinal evidence among Finnish adults. Scandinavian Journal of Psychology, 53(6), 512-522. https://doi.org/10.1111/j. 1467-9450.2012.00969.x.

Lahey, B. B. (2009). Public health significance of neuroticism. American Psychologist, 64(4), 241-256. https://doi.org/10.1037/a0015309.

Lang, F. R., John, D., Lüdtke, O., Schupp, J., \& Wagner, G. G. (2011). Short assessment of the big five: Robust across survey methods except telephone interviewing. Behavior Research Methods, 43(2), 548-567. https://doi.org/10.3758/s13428-011-0066-z.

Loerbroks, A., Schilling, O., Haxsen, V., Jarczok, M. N., Thayer, J. F., \& Fischer, J. E. (2010). The fruits of ones labor: Effort-reward imbalance but not job strain is related to heart rate variability across the day in 35-44-year-old workers. Journal of Psychosomatic Research, 69(2), 151-159. https://doi.org/10.1016/j.jpsychores.2010.03.004.

Mäkikangas, A., Feldt, T., Kinnunen, U., \& Mauno, S. (2013). Does personality matter? A review of individual differences in occupational well-being. Advances in Positive Organizational Psychology, 1, 107-143. https://www.emerald.com/insight/content/doi/10.1108/ S2046-410X(2013)0000001008/full/html.

Matthews, G., Deary, I. J., \& Whiteman, M. C. (2003). Personality traits (2nd ed.). Cambridge University Press. https://doi.org/10. 1017/CBO9780511812736.

McCrae, R. R., \& Costa Jr., P. T. (2008). The five-factor theory of personality. In O. P. John, R. W. Robins, \& L. A. Pervin (Eds.), Handbook of personality: Theory and research (pp. 159-181). New York: NY: Guilford Press.
Morgeson, F. P., \& Humphrey, S. E. (2006). The work design questionnaire (WDQ): Developing and validating a comprehensive measure for assessing job design and the nature of work. Journal of Applied Psychology, 91(6), 1321-1339. https://doi.org/10.1037/0021-9010. 91.6.1321.

Nahrgang, J. D., Morgeson, F. P., \& Hofmann, D. A. (2011). Safety at work: A meta-analytic investigation of the link between job demands, job resources, burnout, engagement, and safety outcomes. Journal of Applied Psychology, 96(1), 71-94. https://doi.org/10. 1037/a0021484.

Netemeyer, R. G., Boles, J. S., \& McMurrian, R. (1996). Development and validation of work-family conflict and family-work conflict scales. Journal of Applied Psychology, 81(4), 400-410. https://doi. org/10.1037/0021-9010.81.4.400.

O'Connor, P. J., Jimmieson, N. L., \& White, K. M. (2018). Too busy to change: High job demands reduce the beneficial effects of information and participation on employee support. Journal of Business and Psychology, 33(5), 629-643. https://doi.org/10.1007/s10869-0179515-8.

Oshio, A., Taku, K., Hirano, M., \& Saeed, G. (2018). Resilience and big five personality traits: A meta-analysis. Personality and Individual Differences, 127, 54-60. https://doi.org/10.1016/j.paid.2018.01. 048.

Ozer, D. J., \& Benet-Martinez, V. (2006). Personality and the prediction of consequential outcomes. Annual Review of Psychology, 57, 401421. https://doi.org/10.1146/annurev.psych.57.102904.190127.

Penney, L. M., David, E., \& Witt, L. A. (2011). A review of personality and performance: Identifying boundaries, contingencies, and future research directions. Human Resource Management Review, 21(4), 297-310. https://doi.org/10.1016/j.hrmr.2010.10.005.

Rammstedt, B., Riemann, R., Angleitner, A., \& Borkenau, P. (2004). Resilients, overcontrollers, and undercontrollers: The replicability of the three personality prototypes across informants. European Journal of Personality, 18(1), 1-14. https://doi.org/10.1002/per. 495.

Richter, D., Metzing, M., Weinhardt, M., \& Schupp, J. (2013). SOEP scales manual, SOEP survey papers, no. 138. Berlin: Deutsches Institut für Wirtschaftsforschung (DIW). https://www.econstor.eu/ bitstream/10419/85279/1/770557678.pdf.

Robins, R. W., John, O. P., Caspi, A., Moffitt, T. E., \& StouthamerLoeber, M. (1996). Resilient, overcontrolled, and undercontrolled boys: Three replicable personality types. Journal of Personality and Social Psychology, 70(1), 157-171. https://doi.org/10.1037/ 0022-3514.70.1.157.

Roth, M., \& von Collani, G. (2007). A head-to-head comparison of bigfive types and traits in the prediction of social attitudes: Further evidence for a five-cluster typology. Journal of Individual Differences, 28(3), 138-149. https://doi.org/10.1027/1614-0001. 28.3.138.

Sârbescu, P., \& Boncu, A. (2018). The resilient, the restraint and the restless: Personality types based on the alternative five-factor model. Personality and Individual Differences, 134, 81-87. https://doi.org/ 10.1016/j.paid.2018.06.002

Sava, F. A., \& Popa, R. I. (2011). Personality types based on the big five model. A cluster analysis over the Romanian population. Cognition, Brain, Behavior, 15(3), 359-384. http://socpers.psihologietm.ro/ PDFs/Sava\%20\&\%20Popa\%20(2011).pdf.

Schaufeli, W. B., \& Bakker, A. B. (2004a). Job demands, job resources, and their relationship with burnout and engagement: A multi-sample study. Journal of Organizational Behavior, 25(3), 293-315. https:// doi.org/10.1002/job.248.

Schaufeli, W. B., \& Bakker, A. B. (2004b). Utrecht work engagement scale: Preliminary manual version 1.1. Occupational Health Psychology Unit Utrecht University, 1-60. https://www. wilmarschaufeli.n1/publications/Schaufeli/Test\%20Manuals/Test manual_UWES_English.pdf. 
Schnabel, K., Asendorpf, J. B., \& Ostendorf, F. (2002). Replicable types and subtypes of personality: German NEO-PI-R versus NEO-FFI. European Journal of Personality, 16(S1), S7-S24. https://doi.org/ 10.1002/per.445.

Taris, T. W., \& Schaufeli, W. B. (2016). The job demands-resources model. In S. Clarke, T. M. Probst, F. Guldenmund, \& J. Passmore (Eds.), Wiley Blackwell handbooks in organizational psychology. The Wiley Blackwell handbook of the psychology of occupational safety and workplace health (p. 157-180). Wiley Blackwell. https:// psycnet.apa.org/record/2015-35805-008.

Topp, C. W., Østergaard, S. D., Søndergaard, S., \& Bech, P. (2015). The WHO-5 well-being index: A systematic review of the literature. Psychotherapy and Psychosomatics, 84(3), 167-176. https://doi. org/10.1159/000376585.

Van Vianen, A. E. (2018). Person-environment fit: A review of its basic tenets. Annual Review of Organizational Psychology and Organizational Behavior, 5(1), 75-101. https://doi.org/10.1146/ annurev-orgpsych-032117-104702.

Van Vianen, A. E., Hamstra, M. R., \& Koen, J. (2016). Personenvironment fits as drivers of commitment. In J. Meyer (Ed.), The
Handbook of Employee Commitment. Cheltenham: Edward Elgar Publishing Limited.

Weiss, A., Bates, T. C., \& Luciano, M. (2008). Happiness is a personal(ity) thing:The genetics of personality and well-being in a representative sample. Psychological Science, 19(3), 205-210. https://doi. org/10.1111/j.1467-9280.2008.02068.x.

Wilmot, M. P., Wanberg, C. R., Kammeyer-Mueller, J. D., \& Ones, D. S. (2019). Extraversion advantages at work: A quantitative review and synthesis of the meta-analytic evidence. Journal of Applied Psychology, 104(12), 1447-1470. https://doi.org/10.1037/ ap10000415.

Wooldridge, J. M. (2010). Econometric analysis of cross section and panel data. Cambridge, Mass: MIT Press. https://www.worldcat. org/title/econometric-analysis-of-cross-section-and-panel-data/oclc/ 47521388? page =citation; https://mitpress.mit.edu/books/ econometric-analysis-cross-section-and-panel-data-second-edition.

Publisher's Note Springer Nature remains neutral with regard to jurisdictional claims in published maps and institutional affiliations. 